\title{
Gene Expression in Patients With Abdominal Aortic Aneurysm - More Than Immunological Mechanisms Involved
}

\author{
M. PRUCHA ${ }^{1}$, P. SEDIVY ${ }^{2}$, P. STADLER ${ }^{2}$, P. ZDRAHAL $^{2}$, V. MATOSKA $^{1}$, H. STRNAD $^{3}$ \\ ${ }^{1}$ Department of Clinical Biochemistry, Hematology and Immunology, Na Homolce Hospital, \\ Prague, Czech Republic, ${ }^{2}$ Department of Vascular Surgery, Na Homolce Hospital, Prague, Czech \\ Republic, ${ }^{3}$ Genomics and Bioinformatics Core Facility, Institute of Molecular Genetics of the \\ Czech Academy of Sciences, Prague, Czech Republic
}

Received March 12, 2018

Accepted February 1, 2019

Epub Ahead of Print March 22, 2019

\section{Summary}

Abdominal aortic aneurysm (AAA) is a serious condition of unclear pathogenesis and progression. Two samples were collected from 48 patients during AAA surgery. One sample was collected from the aneurysm, the other from the aneurysm proximal neck where the tissue did not exhibit any aneurysmal changes. Subsequently, gene expression profiles using microarrays (Illumina) were compared in RNA extracted from the samples. Overall, 2,185 genes were found to be upregulated and 2,100 downregulated; from which 158 genes had a different expression with FDR $<0.05$ (False Discovery Rate) and FC $\geq 2$ (Fold Change). Of this number, 115 genes were over-expressed and 43 under-expressed. The analysis of the gene list based on their biological pathways revealed that the regulation of inflammation was mediated by chemokine and cytokine signaling pathways, the integrin signaling pathway, and $\mathrm{T}$ and $\mathrm{B}$ cell activation. Moreover, a change was identified in the expression of genes involved in both intercellular and intracellular signaling systems.

\section{Key words}

Abdominal aortic aneurysm • Gene expression - Immunological mechanisms • Signaling systems • Pathways

\section{Corresponding author}

M. Prucha, Department of Clinical Biochemistry, Hematology and Immunology, Na Homolce Hospital, Roentgenova 37/2, 15030 Prague 5, Czech Republic. E-mail: miroslav.prucha@homolka.cz

\section{Introduction}

Abdominal aortic aneurysm (AAA) is a serious condition with high mortality rate (Go et al. 2014). The mechanisms of its formation and reasons for its progression have not been clarified yet. Its pathogenesis is multifactorial and still being investigated (Golledge et al. 2010, Maegdefessel et al. 2014, Davis et al. 2014, Kuivaniemi et al. 2015). AAA is a chronic inflammatory disease characterized by inflammatory infiltration of arterial wall, degeneration and elastin fragmentation. The inflammatory process is present in the entire arterial wall and leads to extracellular matrix degradation. The only therapeutic treatment is a surgical procedure: aneurysm removal or use of a stent graft. No pharmacotherapy has been found so far for its effective treatment. Smoking is the most important risk factor for AAA. The only way known to minimize the risk of its progression and rupture is its elimination. Immunological mechanisms represent an important pathogenic factor involved in AAA development. The localized inflammatory reaction in AAA is characterized by the involvement of monocytes, macrophages, $\mathrm{T}$ and $\mathrm{B}$ lymphocytes ( $\mathrm{T}$ and $\mathrm{B}$ cells) and polymorphonuclear cells. The activity of cytokines and leukotrienes, together with the dysregulation of adhesive molecules, result in the damage of smooth arterial muscle, extracellular matrix degeneration, and neovascularization (Shimizu et al. 2006, Rizas et al. 2009, Peshkova et al. 2016, Swedenborg et al. 2011, Lindholt and Shi 2006). The 
Table 1. Demographic and clinical characteristics of patients.

\begin{tabular}{lcccccccc}
\hline & n & m & f & Age (Mean) & DM & HT & CHD & Smoking \\
\hline Patients & 48 & 43 & 5 & 69 & 9 & 40 & 17 & 41 \\
\hline
\end{tabular}

DM - Diabetes mellitus, HT - Hypertension, CHD - Coronary heart disease.

involvement of genetic factors in the development of the disease is indisputable (Blanchard et al. 2000, Sandford et al. 2007, Jones et al. 2017). Receptor mutations for TGF-beta (Transforming Growth Factor beta) and fibrillin were found in both thoracic and abdominal aortic aneurysms (Kim and Stansfield 2017). In recent years, several studies on gene expression in altered aneurysmal tissue have been published. In our opinion, no study has been carried out to compare a sample of aneurysmal and non-aneurysmal aortic tissue in the same patient. Our study compared gene expression in the tissue of AAA and in the healthy part of the proximal neck of the aorta in the same patient.

\section{Methods}

The total of 48 patients with AAA who required an open surgical procedure were included into the study. The average diameter of all aneurysms exceeded $5.5 \mathrm{~cm}$. Two samples ( $5 \times 5 \mathrm{~mm}$ in size) comprising the entire thickness of the arterial wall were collected from each patient - a total of 96 samples were examined - 48 pairs of samples from 48 patients. One sample was obtained from the aneurysm bulge at the largest dilatation macroscopically, the second sample was taken from the proximal neck of the aneurysm without any macroscopically detected aneurysmal changes. Subsequently, both samples underwent Illumina microarray analysis of DNA. Baseline demographics included age and gender; data were also collected with regard to the presence of diabetes (DM), hypertension (HT), coronary heart disease (CHD) and smoking (Table 1).

\section{Analysis of expression profiles}

The total RNA was isolated using RNeasy Micro Kit (Qiagen, MD, USA) according to the manufacturer's protocol. Quality and concentration of RNA were measured with a NanoDrop 2000 spectrophotometer (Thermo Fisher Scientific, MA, USA). The RNA integrity was analyzed by the Bio-analyzer 2100 (Agilent, CA, USA). Only samples with an intact RNA profile were used for expression profiling analyses - RIN $>9$ (RNA Integrity
Number). Illumina HumanHT-12 v4 Expression BeadChips (Illumina, CA, USA) were used for microarray analysis performed in accordance with the standard protocol. In brief, $200 \mathrm{ng}$ RNA was amplified with Illumina TotalPrep RNA Amplification Kit (Ambion, TX, USA) and $750 \mathrm{ng}$ of labeled RNA was hybridized on the chip according to the manufacturer's protocol. The analysis was performed in two biological replicates per group. The raw data were preprocessed using GenomeStudio software (version 1.9.0.24624; Illumina, CA, USA) and the Limma package (Smyth 2004) of Bioconductor (Gentleman et al. 2004), as described elsewhere (Valach et al. 2012). The transcription profiles were background-corrected using the normal-exponential model, which was quantile normalized and variance stabilized using base 2 logarithmic transformation.

\section{Statistics}

A moderated t-test was used to detect transcripts differentially expressed between the samples and controls (within Limma). False discovery rate values were used to select significantly differentially transcribed genes (false discovery rate $(\mathrm{FDR})<0.05)$. The transcription data represent minimum information about a microarray experiment (MIAME) compliant and were deposited in the ArrayExpress database. Gene set enrichment analysis and determination of gene function were performed using Enrichr web service (Chen et al. 2013). The Na Homolce Hospital Ethics Committee approved all protocols and informed consent forms. All patients provided informed consent for participation.

\section{Results}

Different gene expression was established in aneurysmal and non-aneurysmal tissue. Figure 1 shows heat-maps for 1,000 of the most differently expressed genes. The total of 4,285 genes with different gene expression in the aneurysmal and non-aneurysmal tissues of 11,084 transcripts were found. Of this number, 2,185 genes were over-expressed and 2,100 genes underexpressed. Of these genes, 158 were differentially expressed with $\mathrm{FDR}<0.05$ and fold change $(\mathrm{FC}) \geq 2$. Of 
these, 115 were over-expressed and 43 under-expressed. The gene set enrichment analysis (GSEA) method was used to analyze the functions represented by a group of deregulated genes. The analysis performed by means of the protein analysis through evolutionary relationships (PANTHER) and Nature Pathway databases has shown changes in the signal pathways of chemokine and cytokine mediated inflammation reactions, in integrin expression, and $\mathrm{T}$ and $\mathrm{B}$ lymphocyte activation in the inflamed aneurysmal tissue. These findings were in agreement with the analysis integrated in the Kyoto Encyclopedia of Genes and Genomes (KEGG) database. In addition to immunity mechanisms, signal pathways were involved related to the regulation of inflammation, to the cytoskeleton, and signals of intercellular and intracellular pathways.

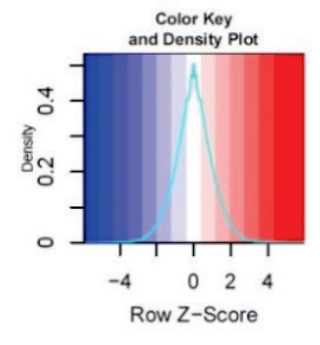

HM: selected 1000/11084probes (RMB), FC >1
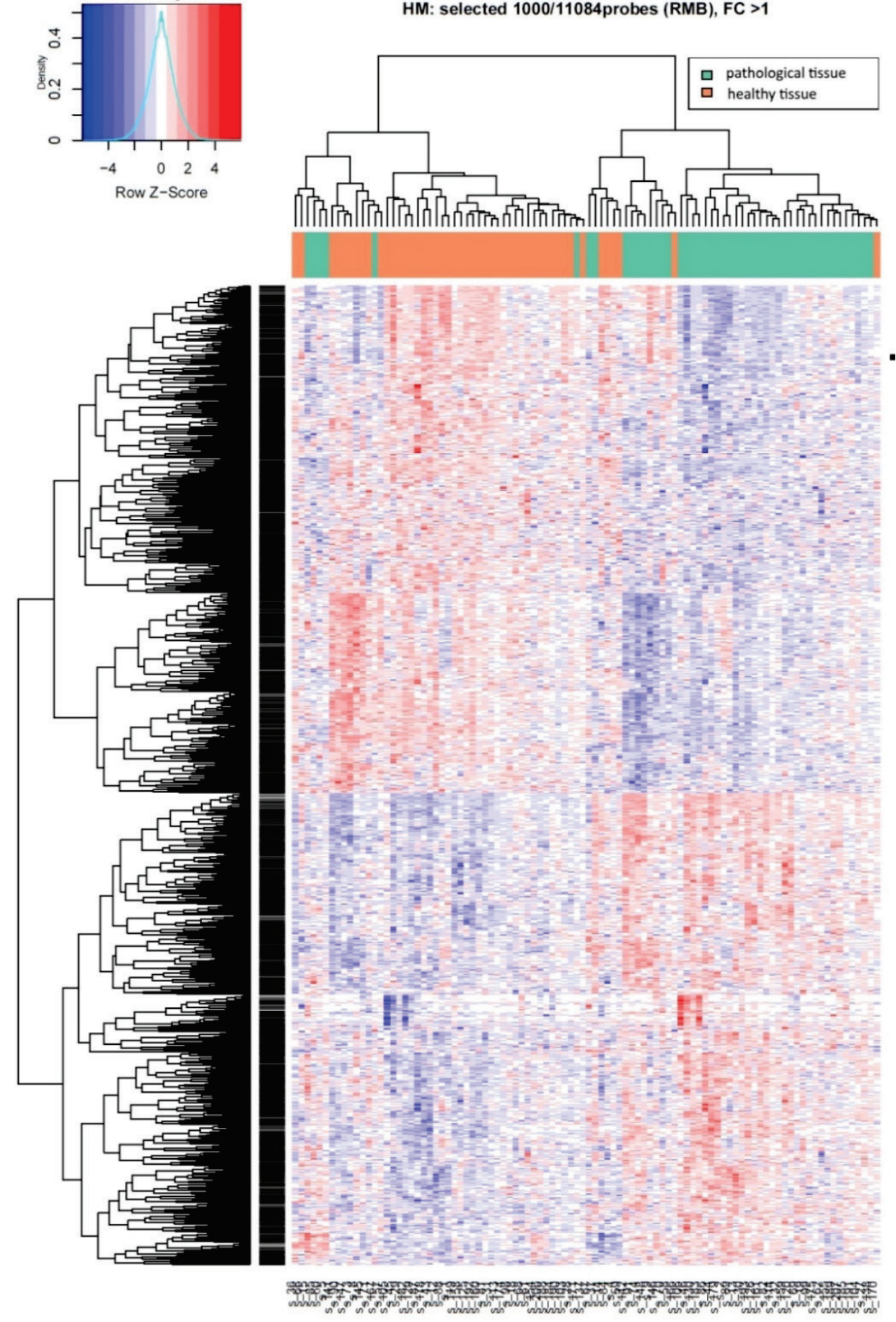

Fig. 1. Heatmaps for 1,000 of the most differently expressed genes. 


\section{Discussion}

A number of studies have been published recently that have dealt with gene expression in AAA patients. Their summary is given in the following reviews (Estrelinha et al. 2014, Kuivaniemi et al. 2014). Gene expression was studied both in patients' plasma and/or biopsy tissue. In our study, we compared aneurysmal tissue with healthy tissue of the affected vessel, i.e. aorta of the same individual. As far as we know, it is the first study of this design. We think that the changes in gene expression manifested in the damaged tissue are more important than those detected in serum. In serum, they are associated either with a very heterogeneous mixed cell population or with an isolated cell population. With regard to the clear compartmentalization of the immune response with AAA patients, a greater importance can be supposed of the changes found directly in pathologically changed tissue similarly to hemato-oncological or oncological diseases. It is no surprise that a significant part of the changed gene expression is related to genes involved in inflammatory processes, i.e. genes for chemokines, integrins, and those for $\mathrm{T}$ and $\mathrm{B}$ cell activation, similarly

Table 2. Selected pathways and differentially expressed genes.

\begin{tabular}{|c|c|c|c|c|c|c|}
\hline KEGG ID & TITLE & No. Genes & No. DEG & $\begin{array}{c}\text { SPIA } \\
\text { p-value }\end{array}$ & SPIA FDR & $\begin{array}{l}\text { SPIA } \\
\text { status }\end{array}$ \\
\hline \multicolumn{7}{|c|}{ Activated pathways } \\
\hline hsa05414 & Dilated cardiomyopathy & 91 & 32 & $1.46 \mathrm{E}-11$ & $9.80 \mathrm{E}-10$ & Activated \\
\hline hsa04062 & Chemokine signaling pathway & 189 & 45 & $5.82 \mathrm{E}-11$ & $2.22 \mathrm{E}-09$ & Activated \\
\hline hsa04060 & Cytokine-cytokine receptor interaction & 265 & 55 & $4.78 \mathrm{E}-10$ & $1.28 \mathrm{E}-08$ & Activated \\
\hline hsa04270 & Vascular smooth muscle contraction & 116 & 34 & $1.60 \mathrm{E}-09$ & $3.06 \mathrm{E}-08$ & Activated \\
\hline hsa04670 & Leukocyte transendothelial migration & 116 & 32 & $1.32 \mathrm{E}-08$ & $2.21 \mathrm{E}-07$ & Activated \\
\hline hsa05166 & HTLV-I infection & 263 & 46 & 2.92E-07 & 4.34E-06 & Activated \\
\hline hsa04064 & NF-kappa B signaling pathway & 92 & 24 & $2.57 \mathrm{E}-06$ & $3.13 \mathrm{E}-05$ & Activated \\
\hline hsa05162 & Measles & 135 & 27 & $3.72 \mathrm{E}-05$ & 0.000416 & Activated \\
\hline hsa04020 & Calcium signaling pathway & 184 & 35 & $6.79 \mathrm{E}-05$ & $7.00 \mathrm{E}-04$ & Activated \\
\hline hsa05416 & Viral myocarditis & 71 & 18 & 0.000143 & 0.00137 & Activated \\
\hline hsa04650 & Natural killer cell mediated cytotoxicity & 138 & 21 & 0.000169 & 0.00151 & Activated \\
\hline hsa05032 & Morphine addiction & 92 & 21 & 0.000196 & 0.00165 & Activated \\
\hline hsa04380 & Osteoclast differentiation & 132 & 26 & 0.00036 & 0.00268 & Activated \\
\hline hsa04660 & $\mathrm{T}$ cell receptor signaling pathway & 108 & 20 & 0.00108 & 0.00725 & Activated \\
\hline hsa04330 & Notch signaling pathway & 47 & 12 & 0.00156 & 0.0095 & Activated \\
\hline \multicolumn{7}{|c|}{ Inhibited pathways } \\
\hline hsa04810 & Regulation of actin cytoskeleton & 213 & 48 & $6.92 \mathrm{E}-14$ & $9.28 \mathrm{E}-12$ & Inhibited \\
\hline hsa04510 & Focal adhesion & 201 & 49 & $6.62 \mathrm{E}-11$ & $2.22 \mathrm{E}-09$ & Inhibited \\
\hline hsa05412 & $\begin{array}{l}\text { Arrhythmogenic right ventricular } \\
\text { cardiomyopathy (ARVC) }\end{array}$ & 74 & 27 & $7.20 \mathrm{E}-10$ & $1.61 \mathrm{E}-08$ & Inhibited \\
\hline hsa04512 & ECM-receptor interaction & 84 & 23 & $2.25 \mathrm{E}-06$ & $3.01 \mathrm{E}-05$ & Inhibited \\
\hline hsa05132 & Salmonella infection & 86 & 19 & 0.00029 & 0.00229 & Inhibited \\
\hline hsa04142 & Lysosome & 121 & 24 & 0.000856 & 0.00603 & Inhibited \\
\hline hsa05100 & Bacterial invasion of epithelial cells & 70 & 16 & 0.0015 & 0.0095 & Inhibited \\
\hline hsa04540 & Gap junction & 89 & 16 & 0.00238 & 0.0122 & Inhibited \\
\hline hsa04070 & Phosphatidylinositol signaling system & 81 & 16 & 0.00961 & 0.0322 & Inhibited \\
\hline
\end{tabular}

KEGG ID - Kyoto encyclopedia of genes and genomes pathway ID, Name - KEGG pathway name, No Genes - Number of genes detected in the experiment and belonging to the pathway, No DEG - Number of differentially expressed genes detected in the experiment and belonging to the pathway, SPIA p-value - SPIA global pathway significance p-value, SPIA FDR - FDR corrected SPIA global pathway significance p-value, SPIA status - SPIA estimate on pathway activation/inhibition. 
to the previously published studies (Biros et al. 2014, Hinterseher et al. 2013, Giusti et al. 2009, Butt et al. 2016, Tanios et al. 2015). Destructive inflammation is the main characteristic of AAA formation and progression; it is therefore understandable that immunological mechanisms are at play. The results show that both B and $\mathrm{T}$ lymphocytes (i.e. both cell and humoral immunity) are involved. Regarding the basic pathogenetical mechanism (chronic inflammation), it was not surprising, e.g. activation of B lymphocytes "promotes AAA by producing immune-globulins, cytokines and metalloproteinases resulting in the activation of macrophages, mast cells and complement pathways (Zhang et al. 2015). Similarly, our study demonstrated the activation of the pathways regarding the chemokine signaling, cytokine receptor interaction, leukocyte transendothelial migration, and Toll like receptor signaling. The selected pathways and differentially expressed genes discussed in the following text are listed in Table 2. When interpreting our results, we focused on the pathways associated with differently expressed genes. When analyzing associated signal pathways in 158 genes with the most significant differences in expression, we found 17 inhibited pathways and 27 activated pathways. Many of these pathways are associated with inter and intracellular signaling. Inter and intra-cellular signaling plays an essential role for the correct function of the cells and thus also tissues (Antebi et al. 2017). What we consider to be important is the evaluation of the associated pathways and trends of the changes found: whether the activation or inhibition is going on. The detection of activated associated signal pathways is the most common trend. Speaking of individual signal pathways, it is interesting to mention a different expression of genes that are associated with dilated cardiomyopathy (DCM). The pathway of dilated cardiomyopathy with differentially expressed genes are on Figure 2. These findings suggest that the two diseases are related. DCM is a disease that is mostly autosomal dominant and more rarely displaying autosomal recessive heredity or X-linked inheritance (Mestroni et al. 2014).

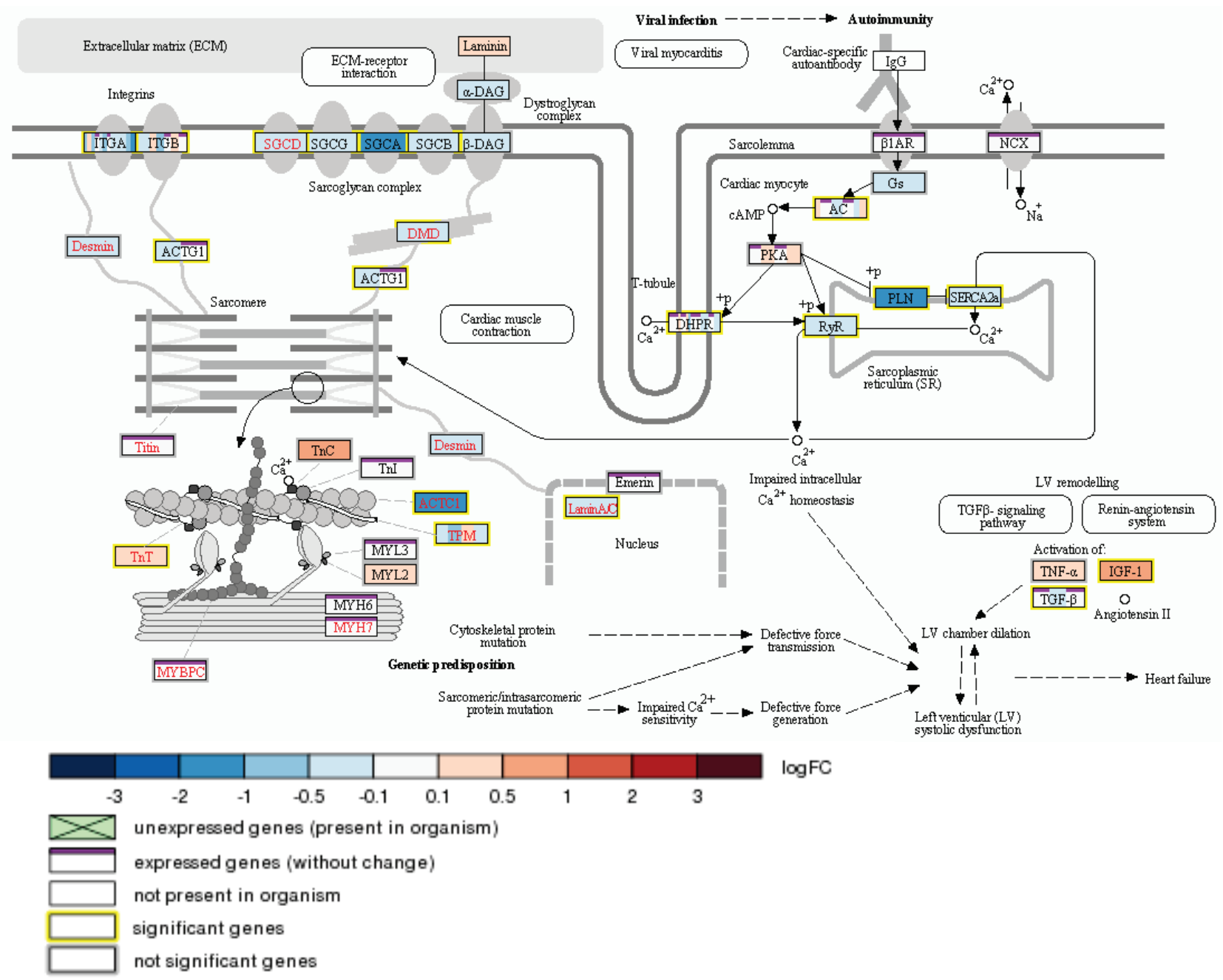

Fig. 2. Pathway of dilated cardiomyopathy. 
More than 40 genes related to DCM (Human Gene Mutation Database) have been detected so far (Tayal et al. 2017). When the genes involved in the signal pathway for DCM were activated, a reduced expression of genes associated with intracellular signaling in aneurysmal tissue was found. Inhibition of the pathways associated with the regulation of cytoskeleton shows a potential insufficient function of the mechanisms modulating actin cytoskeleton, which is a very important mechanism in cardiovascular diseases (Tang and Gerlach 2017). The other example of changes related to intercellular communications is the pathway of Gap junctions (Fig. 3). ions, hormones and neurotransmitters. These intercellular channels comprise a protein family known as connexins. Gap junctions (GJs) represent an intercellular network of protein channels that facilitate the cell-to-cell passage of GJs are surface membrane structures that allow direct communication between cells. They were discovered in

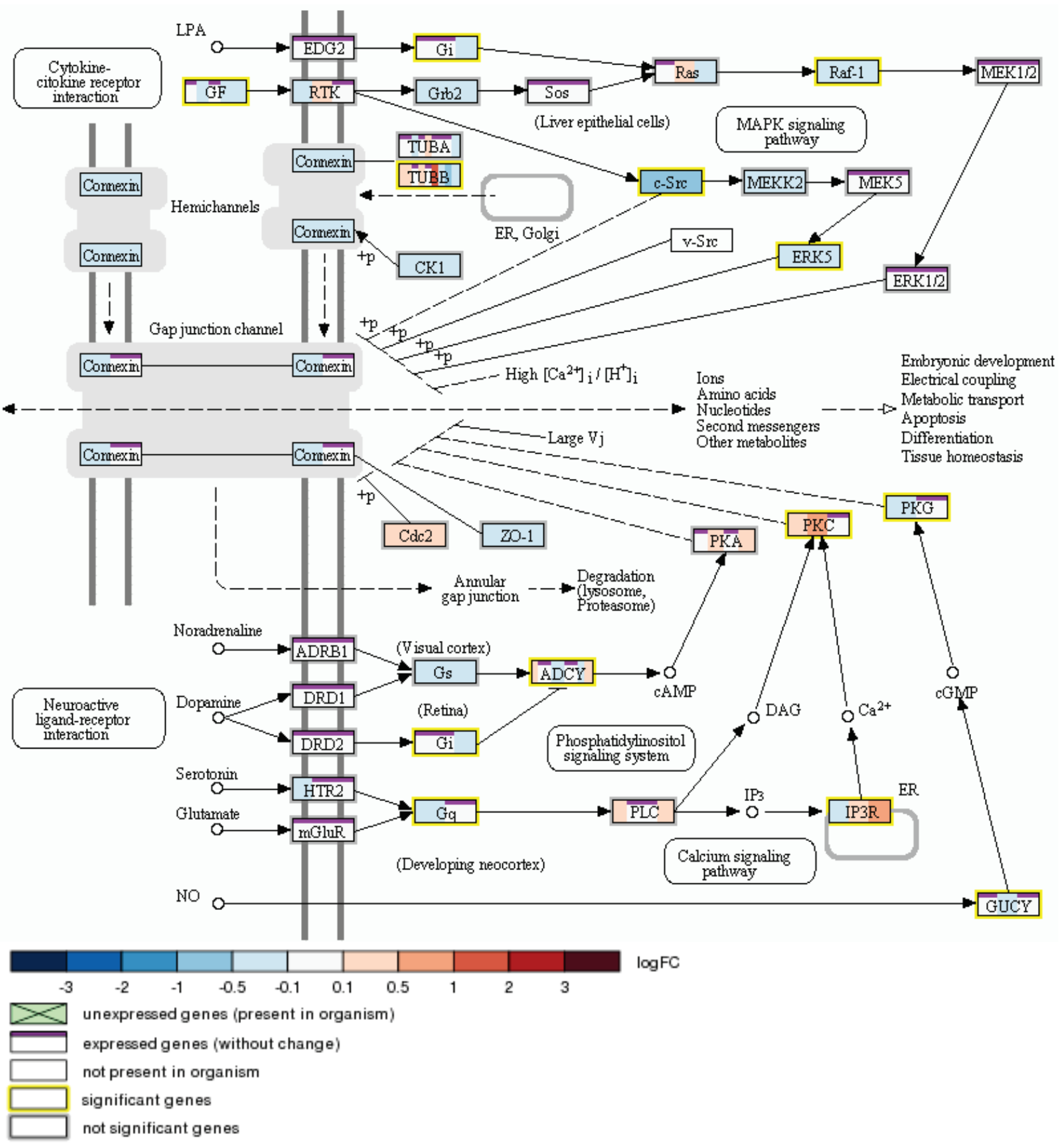

Fig. 3. Pathway of gap junctions. 


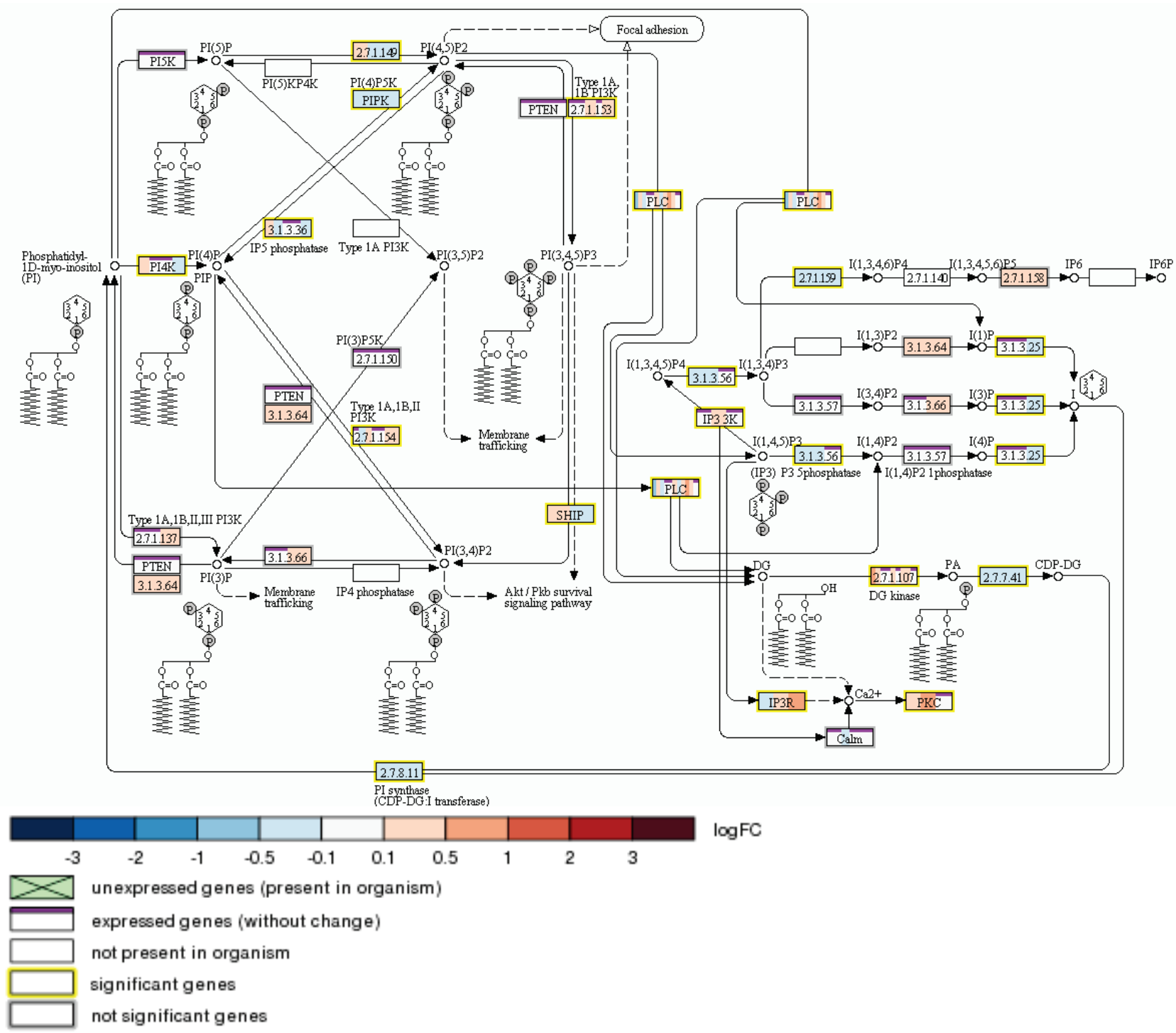

Fig. 4. Pathway of phosphatidylinositol signaling system.

the 1960s following the convergence of the detection of low-resistance electrical interactions between cells and anatomical studies of intercellular contact points (Evans 2015). GJs are significantly involved in controlling vascular functions (Figueroa and Duling 2009). These findings correspond to the study by Lenk et al. (2007) who also proved a significant difference in expression genes associated with GAP and other signaling pathways. The expression of vascular connexins is altered in hypertension. Since our AAA group of patients was characterized by a high incidence of hypertension, it would be interesting to know whether this change is associated with AAA or hypertension. The phosphatidylinositol signaling system is another intracellular signaling system with inhibited expression (Fig. 4). This system regulates various structural and developmental functions but is also centrally involved in a plethora of signal transduction pathways in all eukaryotic models. They are not only precursors of second messengers but also directly interact with many protein effectors, thus regulating their localization and/or activity (Delage et al. 2014). The phosphatidylinositol signaling system is an important lipid signaling system (Wymann and Schneiter 2008). Its altered function in AAA may provide potential evidence of its involvement in AAA pathogenesis. When interpreting the inhibited expression of the abovementioned signaling systems, we can generalize that what we see is a defect in intracellular communication with all its consequences leading to poor cell functioning. We may only speculate about the causes of these changes, which will no doubt be the subject of further studies. One of the interesting outcomes of our study is the 
identification of "local" pathology in relation to a different gene expression. A number of questions arise in this connection. It is known from the clinical practice that there is practically no recurrence with the patients after the operation. Why would the pathology only be limited to a specific section of aorta and significantly depends on the age of the patient? From the existing studies it follows, that aneurysm of chest aorta has significantly lower prevalence and that gene expression TAA differs from gene expression AAA (Matsumoto et al. 2014). It might be caused by a different embryonic origin of chest and abdominal aortas, which leads to a different response of the tissue, e.g. to cytokines.

Limitations of the study. We cannot be sure that the sample obtained from the neck of aneurysm, represented a healthy vessel tissue. Nevertheless, the heatmaps of the analysis performed provide good evidence for the homogeneity of the samples collected from the neck of aneurysm and that were assessed by a surgeon as "normal" tissue. We did not perform protein analysis of the selected genes that were identified as the most significantly differently expressed. Such a selection, however, would have been problematic owing to their high number. Taking samples from the same patient represents a possible limitation of the study if the genetic factors played a significant role in the onset of the disease. While in the thoracic aortic aneurysms (TTA), we already know a specific list of genes that are undoubtedly associated with the pathogenesis of TAA, no mutation predicting the occurrence of AAA has yet been found (Carino et al. 2018). Therefore, it will certainly not be a monogenic disease. The results of recent metaanalysis have shown only a limited number of AAA-associated nucleotide polymorphisms in the studies performed so far (Bradley et al. 2016). The other limitation is the limited number of patients resulted from the financial costs of the study.

In summary, differences in gene expression in the aneurysmal tissue and in the biopsy of healthy tissue of the same patient were found. The changes detected were related to the inflammatory process regulation by means of immune mechanisms - inflammation mediated by chemokine and cytokine signaling pathways, integrin signaling pathway, $\mathrm{T}$ and $\mathrm{B}$ cell activation. Besides, changes in the expression of genes involved in intercellular and intracellular signaling systems were identified. Knowledge of these mechanisms can help get better understanding of the pathogenesis and treatment of AAAs.

\section{Conflict of Interest}

There is no conflict of interest.

\section{Acknowledgements}

This study was supported by an MH CZ - DRO (Hospital Na Homolce - NNH, 00023884), IG144101. Technical support was kindly provided by Petr Sikl.

\section{References}

ANTEBI YE, NANDAGOPAL N, ELOWITZ MB: An operational view of intercellular signaling pathways. Curr Opin Syst Biol 1: 16-24, 2017.

BIROS E, MORAN CS, RUSH CM, GÄBEL G, SCHREURS C, LINDEMAN JH, WALKER PJ, NATAATMADJA M, WEST M, HOLDT LM, HINTERSEHER I, PILARSKY C, GOLLEDGE J: Differential gene expression in the proximal neck of human abdominal aortic aneurysm. Atherosclerosis 233: 211-218, 2014.

BLANCHARD JF, ARMENIAN HK, FRIESEN PP: Risk factors for abdominal aortic aneurysm: results of a casecontrol study. Am J Epidemiol 151: 575-583, 2000.

BRADLEY DT, BADGER SA, MCFARLAND M, HUGHES AE: Abdominal aortic aneurysm genetic associations: mostly false? A systematic review and meta analysis. Eur J Vasc Endovasc Surg 51: 64-75, 2016.

BUTT HZ, SYLVIUS N, SALEM MK, WILD JB, DATTANI N, SAYERS RD, BOWN MJ: Microarray-based gene expression profiling of abdominal aortic aneurysm. Eur J Vasc Endovasc Surg 52: 47-55, 2016.

CARINO D, SARAC TP, ZIGANSHIN BA, ELEFTERIADES JA: Abdominal aortic aneurysm: Evolving controversies and uncertainties. Int J Angiol 27: 58-80, 2018.

CHEN EY, TAN CM, KOU Y, DUAN Q, WANG Z, MEIRELLES GV, CLARK NR, MA'AYAN A: Enrichr: interactive and collaborative HTML5 gene list enrichment analysis tool. BMC Bioinformatics 14: 128, 2013.

DAVIS FM, RATERI DL, DAUGHERTY L: Mechanisms of aortic aneurysm formation: translating preclinical studies into clinical therapies. Heart 100: 1498-1505, 2014. 
DELAGE E, PUYAUBERT J, ZACHWSKI A, RUELLAND E: Signal transduction pathways involving phosphatidylinositol 4-phosphate and phosphatidylinositol 4,5-bisphosphate: convergences and divergences among eukaryotic kingdoms. Prog Lipid Res 52: 1-14, 2013.

ESTRELINHA M, HINTERSEHER I, KUIVANIEMI H: Gene expression studies in human abdominal aortic aneurysm. Rev Vasc Med 3: 77-82, 2014.

EVANS WH: Cell communications across gap junctions: a historical perspective and current developments. Biochem Soc Trans 43: 450-459, 2015.

FIGUEROA XF, DULING BR: Gap junctions in the control of vascular function. Antioxid Redox Signal 11: 251-265, 2009.

GENTLEMAN RC, CAREY VJ, BATES DM, BOLSTAD B, DETTLING M, DUDOIT S, ELLIS B, GAUTIER L, GE Y, GENTRY J, HORNIK K, HOTHORN T, HUBER W, IACUS S, IRIZARRY R, LEISCH F, LI C, MAECHLER M, ROSSINI AJ, SAWITZKI G, SMITH C, SMYTH G, TIERNEY L, YANG JY, ZHANG J: Bioconductor: open software development for computational biology and bioinformatics. Genome Biol 5: R80, 2004.

GIUSTI B, ROSSI L, LAPINI I, MAGI A, PRATESI G, LAVITRANO M, BIASI GM, PULLI R, PRATESI C, ABBATE R: Gene expression profiling of peripheral blood in patients with abdominal aortic aneurysm. Eur J Vasc Endovasc Surg 38: 104-112, 2009.

GO AS, MOZAFFARIAN D, ROGER VL, BENJAMIN EJ, BERRY JD, BLAHA MJ, DAI S, FORD ES, FOX CS, FRANCO S, FULLERTON HJ, GILLESPIE C, HAILPERN SM, HEIT JA, HOWARD VJ, HUFFMAN MD, JUDD SE, KISSELA BM, KITTNER SJ, LACKLAND DT, LICHTMAN JH, LISABETH LD, MACKEY RH, MAGID DJ, MARCUS GM, MARELLI A, MATCHAR DB, MCGUIRE DK, MOHLER ER 3RD, MOY CS, MUSSOLINO ME, NEUMAR RW, NICHOL G, PANDEY DK, PAYNTER NP, REEVES MJ, SORLIE PD, STEIN J, TOWFIGHI A, TURAN TN, VIRANI SS, WONG ND, WOO D, TURNER MB; AMERICAN HEART ASSOCIATION STATISTICS COMMITTEE AND STROKE STATISTICS SUBCOMMITTE. Executive summary: heart disease and stroke statistics - 2014 update: a report from the American Heart Association. Circulation 129: 399-410, 2014.

GOLLEDGE J, NORMAN PE: Atherosclerosis and abdominal aortic aneurysm. Cause, response, or common risk factors? Arterioscl Thromb Vasc Biol 30: 1075-1077, 2010.

HINTERSEHER I, ERDMAN R, ELMORE JR, STAHL E, PAHL MC, DERR K, GOLDEN A, LILLVIS JH, CINDRIC MC, JACKSON K, BOWEN WD, SCHWORER CM, CHERNOUSOV MA, FRANKLIN DP, GRAY JL, GARVIN RP, GATALICA Z, CAREY DJ, TROMP G, KUIVANIEMI H: Novel pathways in the pathobiology of human abdominal aortic aneurysms. Pathobiology 80: 1-10, 2013.

JONES GT, TROMP G, KUIVANIEMI H, GRETARSDOTTIR S, BAAS AF, GIUSTI B, STRAUSS E, VAN'T HOF FN, WEBB TR, ERDMAN R, RITCHIE MD, ELMORE JR, VERMA A, PENDERGRASS S, KULLO IJ, YE Z, PEISSIG PL, GOTTESMAN O, VERMA SS, MALINOWSKI J, ET AL.: Meta-analysis of genome-wide association studies for abdominal aortic aneurysm identifies four new disease-specific risk loci. Circ Res 120: 341-353, 2017.

KIM HW, STANSFIELD BK: Genetic and epigenetic regulation of aortic aneurysms. Biomed Res Int 2017: 7268521, 2017.

KUIVANIEMI H, RYER EJ, ELMORE JR, TROMP G: Understanding the pathogenesis of abdominal aortic aneurysms. Expert Rev Cardiovasc Ther 13: 975-987, 2015.

LENK GM, TROMP G, WEINSHEIMMER S, GATALICA Z, BERGUER R, KUIVANIEMI H: Whole genome expression profiling reveals a significant role for immune function in human abdominal aortic aneurysms. BMC Genomics 8: 237, 2007.

LINDHOLT J, SHI GP: Chronic inflammation, immune response, and infection in abdominal aortic aneurysms. Eur J Vasc Endovasc Surg 31: 453-463, 2006.

LU S, WHITE JV, LIN WL, ZHANG X, SOLOMIDES C, EVANS K, NTAOULA N, NWANESHIUDU I, GAUGHAN J, MONOS DS, OLESZAK EL, PLATSOUCAS CD: Aneurysmal lesions of patients with clonally expanded $\mathrm{T}$ cells abdominal aortic aneurysm contain clonally expanded $\mathrm{T}$ cells. J Immunol 192: 4897-4912, 2014. 
MAEGDEFESSEL L, DALMAN RL, TSAO PS: Pathogenesis of abdominal aortic aneurysms: microRNAs, proteases, genetic associations. Annu Rev Med 65: 49-62, 2014.

MATSUMOTO KI, SATAH K, MANIWA T, TANAKA T, OKUNISHI H, ODA T: Proteomic comparison between abdominal and thoracic aortic aneurysms. Int J Mol Med 33: 1033-1047, 2014.

MESTRONI L, BRUN F, SPEZZACATENE A, SINAGRA G, TAYLOR MR: Genetic causes of dilated cardiomyopathy. Prog Pediatr Cardiol 37: 13-18, 2014.

PESHKOVA JO, SCHAEFER G, KOLTSOVA EK: Atherosclerosis and aortic aneurysm - is inflammation a common denominator? FEBS J 283: 1636-1652, 2016.

RIZAS KD, IPPAGUNTA N, TILSON MD 3RD: Immune cells and molecular mediators in the pathogenesis of the abdominal aortic aneurysm. Cardiol Rev 17: 201-210, 2009.

SANDFORD RM, BOWN MJ, LONDON NJ, SAYERS RD: The genetic basis of abdominal aortic aneurysms: a review. Eur J Vasc Endovasc Surg 33: 381-390, 2007.

SHIMIZU K, MITCHELL RN, LIBBY P: Inflammation and cellular immune responses in abdominal aortic aneurysms. Arterioscler Thromb Vasc Biol 26: 987-994, 2006.

SMYTH GK: Linear models and empirical Bayes methods for assessing differential expression in microarray experiments. Stat Appl Genet Mol Biol 3: Article 3, 2003.

SWEDENBORG J, MÄYRÄNPÄÄ MI, KOVANEN PT: Mast cells: important players in the orchestrated pathogenesis of abdominal aortic aneurysms. Arterioscler Thromb Vasc Biol 31: 734-740, 2011.

TANG DD, GERLACH BD: The role and regulation of the actin cytoskeleton, intermediate filaments and microtubules in smooth muscle cells migration. Respir Res 18: 54-66, 2017.

TANIOS F, PELISEK J, LUTZ B, REUTERSBERG B, MATEVOSSIAN E, SCHWAMBORN K, HÖSEL V, ECKSTEIN HH, REEPS C: XC4: a potential marker for inflammatory activity in abdominal aortic aneurysm wall. Eur J Vasc Endovasc Surg 50: 745-753, 2015.

TAYAL U, PRASAD S, COOK SA: Genetics and genomics of dilated cardiomyopathy and systolic heart failure. Genome Med 9: 20-34, 2017.

VALACH J, FÍK Z, STRNAD H, CHOVANEC M, PLZÁK J, CADA Z, SZABO P, SÁCHOVÁ J, HROUDOVÁ M, URBANOVÁ M, STEFFL M, PAČES J, MAZÁNEK J, VLČEK C, BETKA J, KALTNER H, ANDRÉ S, GABIUS HJ, KODET R, SMETANA K JR, GÁL P, KOLÁŘ M: Smooth muscle actin-expressing stromal fibroblasts in head and neck squamous cell carcinoma: increased expression of galectin-1 and induction of poor prognosis factors. Int J Cancer 131: 2499-2508, 2012.

WYMANN MP, SCHNEITER R: Lipid signalling in disease. Nat Rev Mol Cell Biol 9: 162-176, 2008.

ZHANG L, WANG Y: B lymphocytes in abdominal aortic aneurysms. Atherosclerosis 242: 311-317, 2015. 